\title{
A Comprehensive Overview of the Impacting Factors on a Lithium-Ion-Battery's Overall Efficiency
}

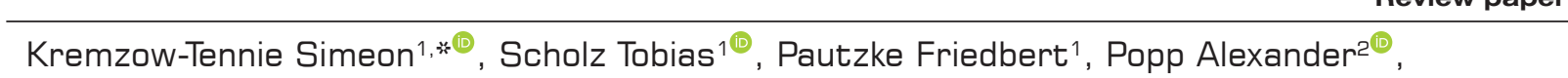 \\ Fechtner Heiko ${ }^{2(0)}$, Schmuelling Benedikt ${ }^{(1)}$ \\ ${ }^{1}$ Bochum University of Applied Sciences, Electric Vehicle Institute, Germany \\ 2University of Wuppertal, Chair of Electric Mobility and Energy Storage Systems, Germany
}

Received: December 22, 2021; Accepted: January 29, 2022

\begin{abstract}
This comprehensive overview of the impacting factors on lithium-ion-battery's (LIB) overall efficiency presents the most relevant influencing factors on a battery's performance. Dissected into their respective short-term and long-term influences, the working principles behind the efficiency influencing factors are presented. With a strong focus on battery characterisation, charge-profiles and battery management systems (BMSs), the authors present results of their own practical research with a detailed literary analysis, allowing a broad coverage of the complex topic. Finally, the authors present a principle model that indicates the interactions be-tween the different involved components of the battery.
\end{abstract}

Keywords: battery simulation • battery efficiencies • component analysis • simulation technologies • battery analysis

\section{Introduction}

The numbers of electric vehicles (EV) are rising all over the world, yet still, many potential customers mention that range anxiety is an important reason holding them back from switching to an EV (Pevec et al., 2020, 2019). A recent study unveiled that around $35 \%$ of the citizens in Germany consider vehicle range as a limiting factor when considering the purchase of an EV (Burkert et al., 2021). Therefore, research in areas such as fast charging, lithiumion-battery (LIB) energy efficiency, as well as EV's overall efficiency, have become increasingly important in recent years. Fast charging is a key step to reduce the recharging of an EV to a comparable time interval of refuelling an internal combustion engine vehicle (ICEV). Furthermore, a sufficient network of fast-charging stations is required along highways in order to satisfy the expected requirement of electric energy for long-distance travelling (Jochem et al., 2019). Modern EV can achieve similar driving distances to their ICEV counterparts, even though the energy density of an EVs traction battery is much smaller than that of the fossil fuel in an ICEV. Despite the energy density disadvantage, similar driving ranges can be achieved thanks to the higher overall efficiency of an EV (Albatayneh et al., 2020; Kremzow-Tennie et al., 2020). To further improve EV range, it is important to also improve the efficiencies of these vehicles. Therefore, a full understanding of the efficiency influencing factors of each relevant component is needed. In a previous publication, the authors analysed the driving resistances and identified the influence of weight, aerodynamics and power losses in the electrical system on a vehicle's overall efficiency. However, the traction battery was not analysed in greater detail, which is the aim of this research.

Regarding the efficiency terminology, three different efficiencies can be found when analysing batteries. These can be dissected into coulombic efficiency, voltaic efficiency and energy efficiency. The coulombic efficiency

\footnotetext{
*Email: simeon.kremzow-tennie@hs-bochum.de
} 
describes the relation of the discharge capacity to the charged capacity of the same cycle. Calculation of the coulombic efficiency is done using the equation

$$
\eta_{C}=\frac{\int_{t_{\text {start }}}^{t_{\text {end }}} I_{\text {discharge }} * d t}{\int_{t_{\text {start }}}^{t_{\text {end }}} I_{\text {charge }} * d t}
$$

and is given as a unitless factor between 0 and 1 (Mu and Xiong, 2018; Wang et al., 2021). According to the ISO12405-4, the energy efficiency of a LIB can be calculated using the equation

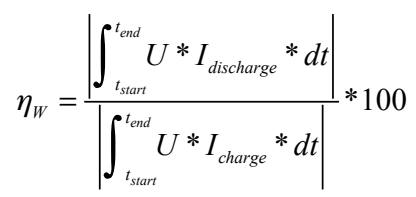

and for uncycled LIBs usually results in between $75 \%$ and $90 \%$ (ISO 12405-4, 2018). The voltage efficiency is the relation between the average voltage over the whole discharge process and the average voltage over the whole charge process of the same cycle. Calculation of the voltage efficiency

$$
\eta_{V}=\frac{\int_{t_{\text {start }}}^{t_{\text {end }}} U_{\text {discharge }} * d t}{\int_{t_{\text {start }}}^{t_{\text {end }}} U_{\text {charge }} * d t}
$$

is done using the stated equation. As the efficiency of a LIB and especially the components influencing the overall efficiency varies with the battery's age, specific percentual identifications are nearly impossible to make, as these are not only specific to each type of battery but also dependent on the specific usage scenario. Therefore, we aim to give a comprehensive insight into the factors influencing the overall efficiency of a LIB, with a focus on the battery and its associated battery management system (BMS). Based on this, it is not the aim to name the quantitative influence on a specific battery cell, but to give a general comprehensive overview of the factors that influence a LIBs overall efficiency directly or indirectly.

\section{Related Works}

The authors' study on the influencing factors on energy consumption of EV forms the basis for this detailed publication in which the driving resistances and power losses in EV were analysed. Furthermore, the publication included a verified simulation model that was used to simulate a full vehicle and vary its parameters to understand their influence on the vehicle's energy consumption. As the focus of this publication was on the overall vehicle efficiency, only the overall efficiency of the traction battery was mentioned (Kremzow-Tennie et al., 2020). To get into greater detail on LIBs, which is the authors' main area of research, this publication analysed the efficiency influencing factors by combining literary analysis, battery modelling and battery data collection. Lu et al. also researched EV energy efficiencies with a focus on the traction battery, yet their research was focused on the then popular NickelMetal Hydride (NiMH) batteries, which have different properties compared to the newer and more powerful LIBs (Lu et al., 2010). Another research on energy efficiencies of LIB has been performed by (Redondo-Iglesias et al., 2017), who researched the impact of calendar ageing on electric mobility energy efficiencies. Section 4 of this publication contains the data collection and modelling of LIBs. Similar to the authors' approach, (Bilansky and Lacko, 2020) designed and simulated a cyclic battery tester, though the model used in their work is based on the MATLAB generic battery model, whereas the authors' model is an equivalent circuit based model using cubic spline interpolated datasets. Furthermore, the authors of this publication have built several simulation models, featuring different levels of precision that implement battery parameters measured in real driving scenarios (Guenther et al., 2021; Scholz et al., 2021), as well as precisely controlled battery test systems (Kremzow-Tennie et al., 2021). Thus, this work 
can be considered an extension of the work presented by Bilansky and Lacko, as it advances the approach of battery testing into different testing scenarios and their respective measurement data generation. This is especially important, as the different testing scenarios, such as fast charging result in different ageing mechanisms and thus differentiate in their influence of the severity on the battery's overall efficiency.

\section{Efficiency Influencing Factors}

Understanding and researching the efficiency influencing factors of a LIB is an important step to further promote electric mobility, as well as to evaluate losses during specific usage scenarios. This section aims to dissect the battery and its BMS into their respective parts and analyses how the efficiency is influenced through these based on previously performed research. Therefore, this chapter lays the basis of the literary analysis that is required to design a battery model that can properly evaluate the different efficiency influencing factors. By culminating the knowledge on the different battery components and how they are influenced the reader shall gain the necessary understanding required for the creation of the principle model presented in Section 5.

\subsection{Capacity}

The capacity describes the usable energy stored inside of a battery and therefore is one of the crucial factors for the battery's application. Stated in Ah, the charged capacity can be measured through the integration of the charging current over its respective charging time. The available capacity of a battery cell is also one of the key parameters to describe its state-of-health $(\mathrm{SOH})$, which is mostly used to evaluate a cell's further usability in an electric vehicle, second life application or if it has reached the end of its life. $\mathrm{ASOH}$ in dependence to the capacity is often stated as $\mathrm{SOH}(\mathrm{C})$. In EV technology a $\mathrm{SOH}(\mathrm{C})$ of $80 \%$, meaning only $80 \%$ of the battery's original capacity is still available, means its end-of-life threshold has been reached according to the United States Advanced Battery Consortium (USABC) (Zhu et al., 2021). As regards the battery's lifetime, the capacity degrades due to chemical side reactions such as lithium-plating, the creation of the solid-electrolyte-interface (SEI) and other degradation effects such as pore clogging and surface cracking, which are all directly proportional to the wear and tear over time. The other main influences are the ambient temperature, upper and lower cut-off voltage, as well as charge and discharge current (Hermann et al., 2019; Kremzow-Tennie et al., 2021; Liu et al., 2016; Notten et al., 2005; Petzl et al., 2015; Reniers et al., 2019).

The influence of a battery's capacity on its efficiency is strongly dependent on the battery's $\mathrm{SOH}$, as a reduction of the available capacity reduces the available range an EV can drive. Furthermore, lower temperatures further inhibit the full usability of the available capacity, thus reducing the potential range even further.

\subsection{Lithium-plating}

One of the most notable physical influencing factors is considered lithium-plating, which describes the deposition of lithium-ions at the graphite layer of the cell's negative electrode. Lithium-plating itself does not influence the efficiency directly, but it influences the ageing of a battery and thus influences the internal resistance and usable capacity, which then influence the efficiency of a battery. During charging, positively charged lithium-ions intercalate into the grid structure of the anode, which under normal circumstances, takes place without issues. These normal circumstances are the manufacturer specified temperature, upper cut-off voltage, as well as the charging current. It has to be noted, however, that lithium-plating can also occur during battery usage within the manufacturer's guidelines, though at a lower rate than when compared to high power loads (Schuster et al., 2015). When the cell temperature is reduced, the chemical reaction speed is also reduced, a behaviour which is explained by the Arrhenius equation (Arrhenius, 1889). The reduction of reaction speed results in a slower intercalation process and therefore a collection of lithium-ions at the negative electrode. This collection itself is no threat to the cell's behaviour if the charging procedure is stopped and the cell can rest. During this rest period, the accumulated lithium-ions can then slowly intercalate into the graphite grid structure. If there is no rest period, or the charging current is too large the accumulated and not intercalated lithium ions, it can be reduced to metallic lithium, which is considered lithium-plating (Liu et al., 2016; Petzl et al., 2015; Reniers et al., 2019). This process is still reversible and given enough relaxation time, or a small discharge current (lithium-stripping), the reduced lithium-ions can intercalate into or be stripped from the anode (Shen et al., 2012; Wang et al., 2016). Irreversible lithium-plating happens when the collected lithium-ions cannot intercalate into the anode and react with the cell's electrolyte, which results in the 

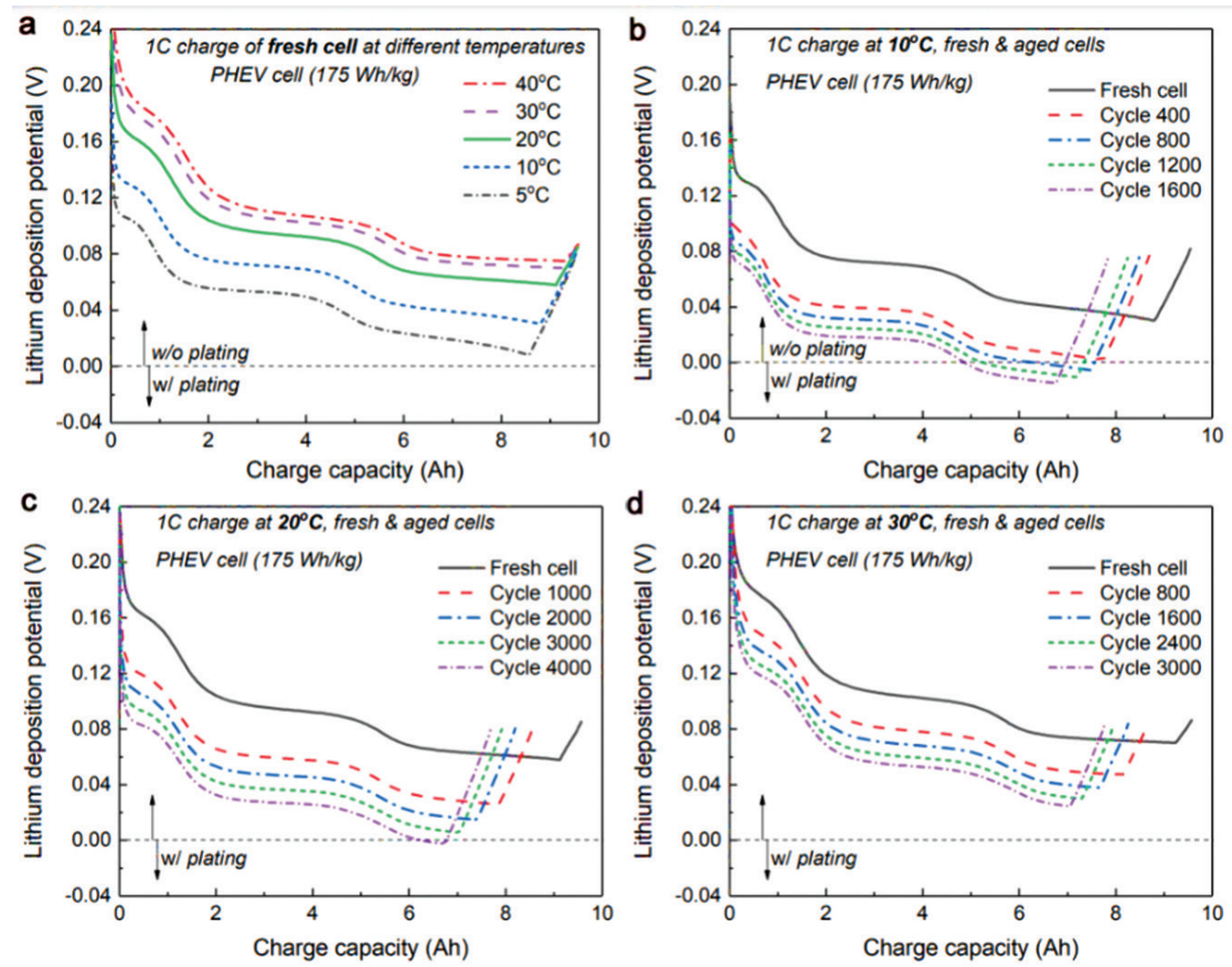

Fig. 1. Lithium deposition potential at different temperatures, charge rates and cell ages of a hybrid electric vehicle (Yang and Wang, 2018).

solid electrolyte-interphase (SEI) (Reniers et al., 2019). This and the disconnection of the material from the anode passivates the material, which is then irreversibly lost from the chemical process. As visible in Figure 1, lithium plating is dependent on the lithium deposition potential, also known as anode potential, which is when falling $<0 \mathrm{~V}$ significantly increases lithium-plating (Hermann et al., 2019). Furthermore, with the increasing age of a battery cell, the lithium deposition potential is reduced, thus promoting lithium plating even further (Yang and Wang, 2018). Additionally, it becomes visible that towards the end of the charge the risk of lithium plating is greater than at lower SOCs, resulting in the need for charge rate reductions at high SOC values (Liu et al., 2016; Notten et al., 2005; Petzl et al., 2015). As mentioned, several other side reactions occur during battery usage. However, since the authors focus their research on the electrical behaviour of a battery and thus do not observe chemical reactions such as lithium-plating and the creation of the SEI in their laboratory environments, these won't be considered in the greatest possible detail here. To measure the amount of lithium-plating that occurred over a battery's lifetime, cells are usually disassembled and their core components are analysed for indication of plating or highly sensitive measurement equipment has to be used (Hu et al., 2020).

\subsection{Open-circuit voltage}

The open-circuit voltage (OCV) is a SOC-dependent parameter that displays a battery's electric output when no load is applied, thus modelling the ideal voltage behaviour without any losses. Due to its correlation to the SOC, the OCV is often used by BMS to evaluate the current SOC when no load is applied to the battery. Based on factors such as the capacity and side reactions mentioned in the previous chapter, the OCV is dependent on the $\mathrm{SOC}, \mathrm{SOH}$, current direction and battery temperature (Xing et al., 2014; Zhang et al., 2018). The exemplary dependence of a LIBs discharge OCV curve on the temperature can be seen in Figure 2, which shows the biggest deviation between voltage values at lower SOC values. Furthermore, it can be seen that the lower cut-off voltage differs significantly, which results in a greater amount of capacity that cannot be withdrawn from the battery at lower temperatures. At higher temperatures the lower cut-off voltage is lower, thus allowing more capacity to be discharged from the battery (Ma et al., 2018). 


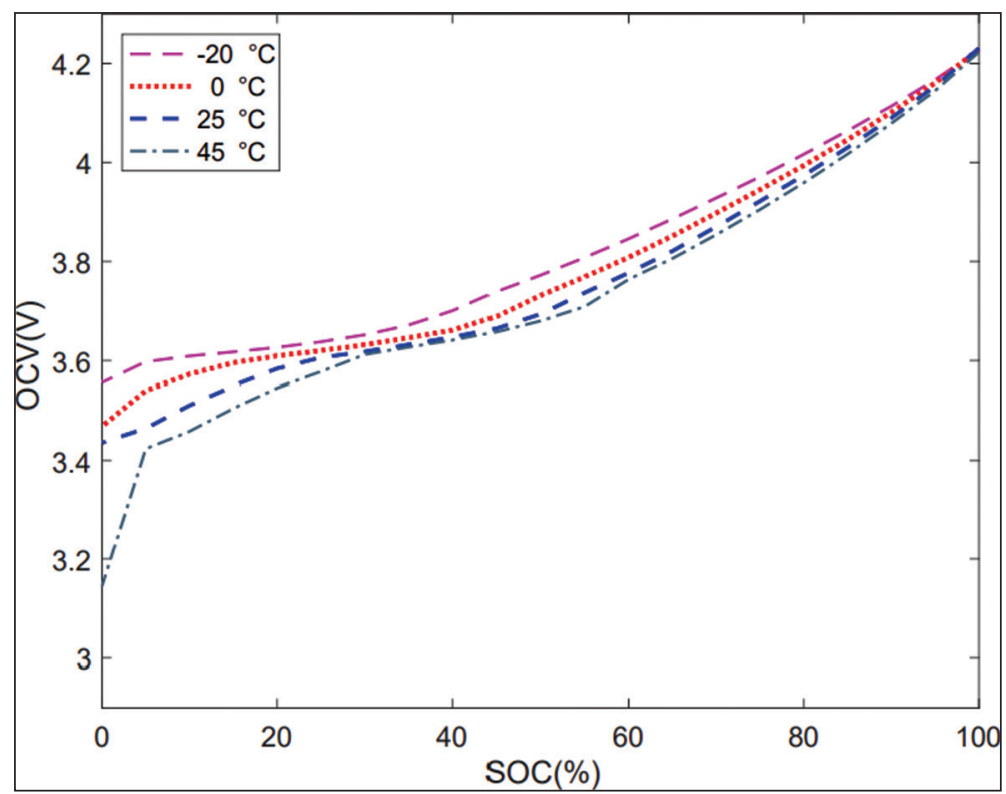

Fig. 2. Discharge OCV curve over the SOC for different temperatures (Zhang et al., 2018).

Furthermore, it has to be noted that the voltage range in which a LIB is operated or stored has an indirect influence on the efficiency of the LIB, as this can, for example, favour the ageing of a LIB, which will then lead to a decrease in efficiency.(Juarez-Robles et al., 2020a; Xu et al., 2018) Thus, reducing the charging cut-off voltage in the application leads to a significantly higher cycle stability.(Gao et al., 2017; Juarez-Robles et al., 2020a) This phenomenon can also be transferred to the discharge cut-off voltage (Juarez-Robles et al., 2020b).

\subsection{Cell and ambient temperature}

Cell and ambient temperature are other important influencing factors, which need to be taken into account when discussing the energy of a LIB. Manufacturers usually state a recommended temperature range for operation and another for storage. The biggest difference usually is the lower temperature value for the storage range. As the storage temperature is most interesting when it comes to the analysis of calendric ageing, this chapter looks into the operational temperature range, which has a more significant influence on the battery's performance and usability. It should however be mentioned that the higher temperatures promote ageing, as visible in Figure 3, which shows the calendric ageing of a commercial cells stored at different temperatures and SOCs.

As shown in Figure 2, as well as Figure 5c and Figure 5d, the battery's OCV and internal resistance are influenced directly by its temperature, which results in a direct influence on the battery's efficiency (Hossain Ahmed et al., 2015; Liu et al., 2014; Ma et al., 2018; Petzl et al., 2015). Ambient and thus resulting from it the cell temperature significantly influences the discharge behaviour of a LIB, which can be seen in Figure 4 where the dependence of the dischargeable capacity, terminal voltage and cell temperature is displayed.

It becomes visible, that at $-20^{\circ} \mathrm{C}$ the terminal voltage shows a significant voltage drop right at the beginning of the discharge, and only a discharged capacity of $<1.5 \mathrm{Ah}$ could be measured. This can be explained by the significant reduction of reaction speed. At higher cell temperatures and therefore higher reaction speeds, for example at $40^{\circ} \mathrm{C}$ the maximum capacity could be discharged from the cell. At such high temperatures, not only the reaction speed of the cell is increased but also the internal resistance is found to be lower at lower temperatures (Hermann et al., 2019; Hossain Ahmed et al., 2015; Kremzow-Tennie et al., 2019; Mahmud et al., 2017; Nikolian et al., 2016; Wang et al., 2017). As mentioned earlier and visible in Figure 1, lower temperatures also promote lithium-plating as the lithium deposition potential is reduced at these levels. Together with the increased internal resistance and reduced reaction speed the amount of energy that can be charged into or discharged from the battery is reduced, which therefore reduces the overall efficiency of the battery. Depending on the charge or discharge current, the battery faces a temperature increase due to the ohmic resistance. This temperature increase depends on several physical factors of the battery, such as its size, weight, mass fraction of its chemical components, specific heat capacity, temperature coefficient, heat transfer coefficient, current battery temperature, ambient temperature and internal 


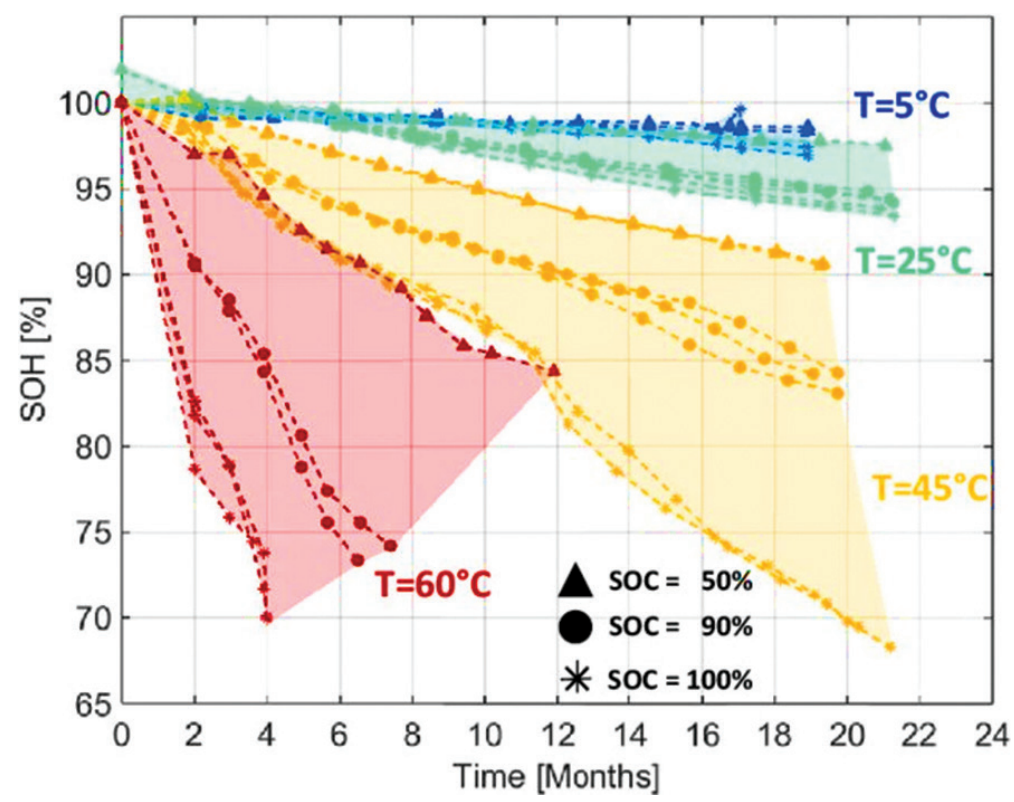

Fig. 3. Calendric ageing of a commercial 16 Ah cell at different temperatures and different SOC values (Matadi et al., 2017).

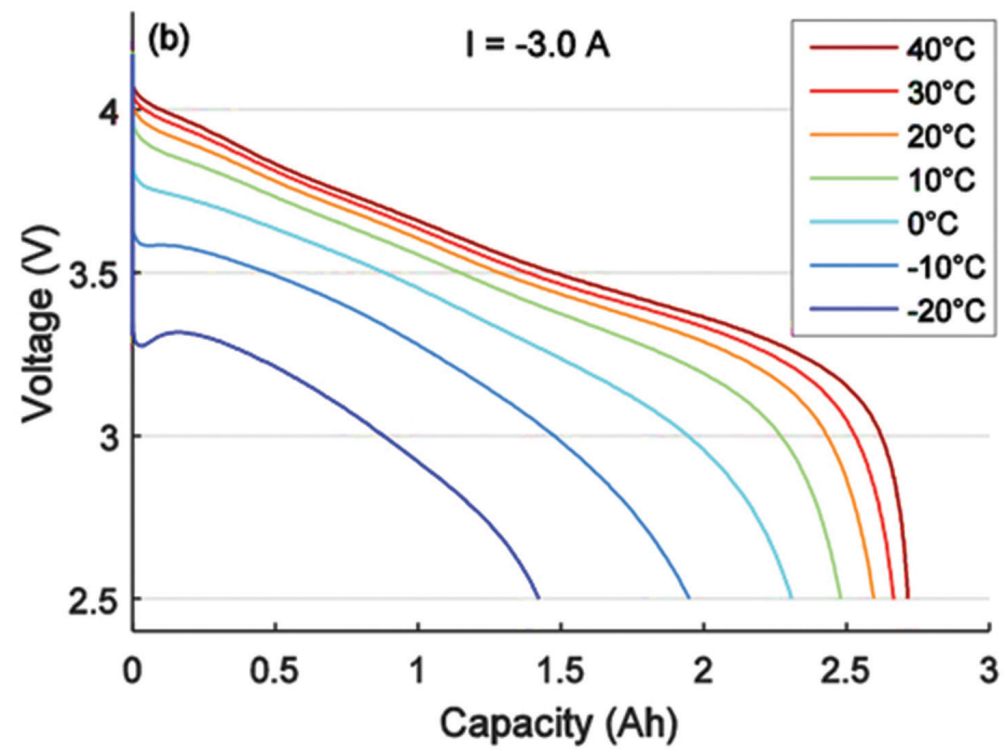

Fig. 4. Discharged capacity at different cell temperatures with the correlating terminal voltage of a 2.8 Ah Panasonic NRC18650PD cell ('BU-502, 2010).

resistance in dependence on the SOC (Kim et al., 2011; Mahmud et al., 2017; Zhang et al., 2018). During charging and discharging, the ambient temperature and thus the resulting cell temperature also have shown to be a big influence on the charging efficiency, which have been mainly explained in the previous sections. (Trentadue et al., 2018; Yang et al., 2018).

\subsection{Internal resistance}

The internal resistance of a cell concerning its use in an EV has a significant influence on the power losses, heat generation, as well as extractable energy, and the possible performance of the system. (Barré et al., 2013; lora and Tribioli, 2019) The internal resistance is influenced by several factors, such as the temperature (de Hoog et al., 2018; Ma et al., 2018; Mahmud et al., 2017), the current SOC (Hossain Ahmed et al., 2015; Liu et al., 2014) and the 

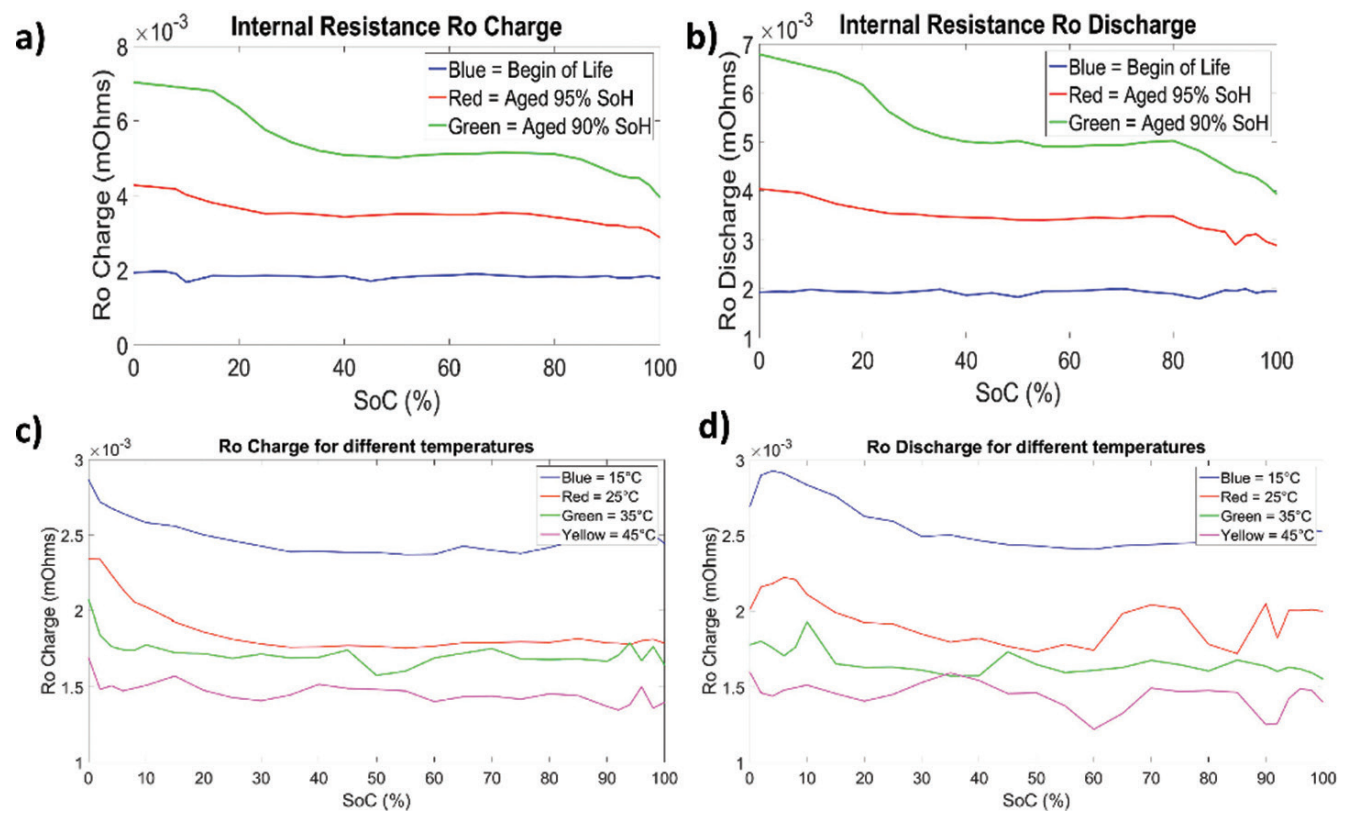

Fig. 5. Behaviour of a LIBs internal resistance in dependence on SOH and temperature (Nikolian et al., 2016).

SOH (Noura et al., 2020; Nuhic et al., 2013). Additionally, the internal resistance is affected by calendric ageing as well as cyclic ageing. Furthermore, LIBs are characterised by different charging and discharging resistances, which accordingly lead to different losses during the charging and discharging process. (Barai et al., 2018; Nikolian et al., 2016). Due to this multivariate dependence of the internal resistance, a statement about the pulse load capacity, the cold or hot start properties and also the removable capacity in the load case can be derived directly from it. The influences on the internal resistance are shown in Figure 5.

As visible in Figure $5 a$ and $b$, the internal resistance changes significantly when the cell is ageing, which is caused by reactions such as lithium-plating and SEI creation, which are influenced by the load that is put onto the cell (Wang et al., 2017; Yang and Wang, 2018). Furthermore, it can be seen in Figure 5c and d, how the cell's temperature influences the internal resistance. The internal resistances which increase at lower temperatures are caused by the reduction in reaction speed, which can be calculated using the Arrhenius equation. With an increase in temperature, the reaction speed also increases, resulting in a reduction of the internal resistance (Arrhenius, 1889; Mahmud et al., 2017). Such as the available capacity of a cell, the value of the internal resistance is also used for a SOH estimation. In this case, the end-of-life threshold is defined by a $100 \%$ increase of internal resistance. This so-called $\mathrm{SOH}(\mathrm{R})$ can also be used for estimating a battery's further in-vehicle usage or deciding on secondlife applications or recycling.

\subsection{Charging profiles}

Different charging profiles result in different efficiency levels to be reached, which are dependent on the charge current and duration. An example of different charging procedures can be found in Figure 6 . To evaluate the efficiency two charging applications shall be considered. The first application can be considered the normal charge to $100 \%$ SOC that is used for most lithium battery applications such as mobile devices and EV. The other application can be considered fast charging, which has become among the most desired achievements in the promotion of electric mobility. The ability to quickly recharge the vehicle without long-standing times is desired by many applicants of EVs. During fast charging the battery is usually only charged to $80 \%$ SOC at a very high current, in order not to overcharge the battery. Depending on the chosen procedure the battery is charged to $100 \%$ SOC at a lower current or the charging is completely stopped at $80 \%$ SOC.

One of the most efficient charging profiles, when performed correctly, is the Constant Current Constant Voltage (CCCV) profile, which charges the battery with a constant current (CC) phase until it reaches the charge cut off voltage. Afterwards the charger changes into the constant voltage (CV) phase, during which the charging current continuously decreases as the difference between the terminal voltage of the cell and the applied CV decreases as 

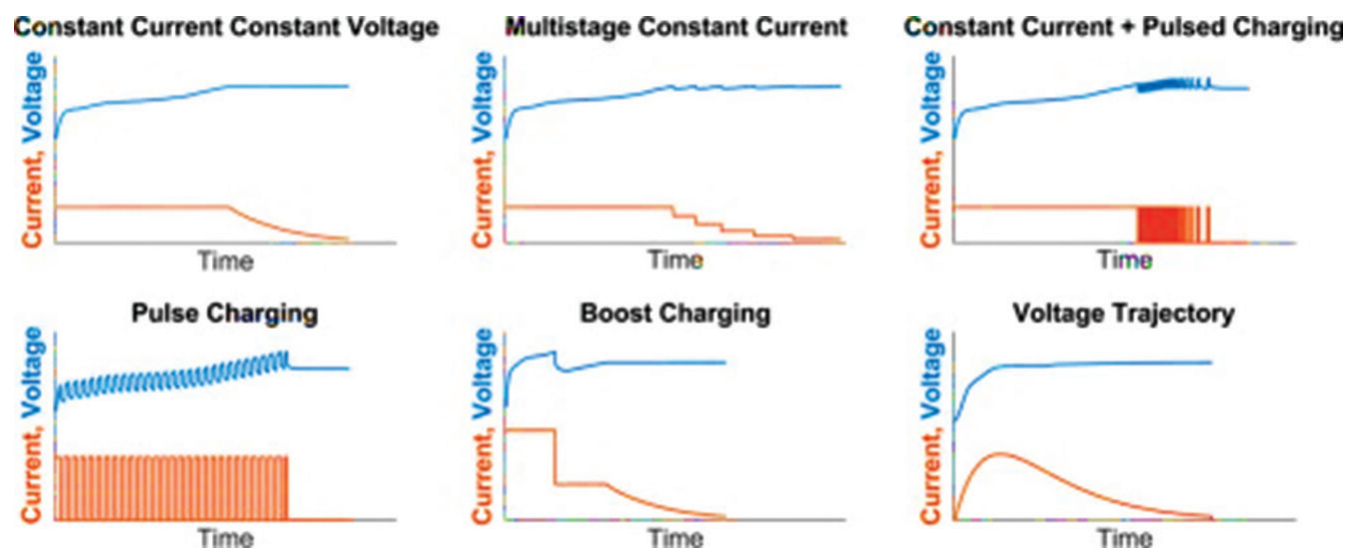

Fig. 6. Different normal and fast charging profiles of LIBs (Keil and Jossen, 2016).

well. This ensures that the battery is not overcharged, as well as reaches the full charge at a very relaxed rate, thus reducing the risk of lithium-plating caused by high currents at high SOC values (see chapter 3.2). Due to the small current at the end of the charge and depending on the set cut-off current threshold, the battery can be charged very efficiently and therefore can significantly reduce losses towards the end of the charge (Shen et al., 2012). Due to its ease of implementation and integrated overcharge protection, the CCCV profile is used as the standard profile for most applications.

The Multistage Constant Current (MCC) profile is one of the first profiles designed to reduce the charging time compared to the CCCV profile. The first stage of the profile charges the battery up to its cut-off voltage and then reduces the current to a lower, but fixed value. In this following stage, the battery is charged until it reaches the cut-off voltage again and the current is reduced once more. This is done until the desired number of stages has been reached and the battery is considered fully charged. Due to the CC in the respective stages, the battery can be charged faster than with the compared CCCV profile. Research has shown that a charge time reduction of up to $12 \%$ can be achieved (Khan, 2016). However, since the current is not continuously reduced, the CC in the different stages will result in a higher overall battery temperature and thus promote ageing and lithium-plating (Keil and Jossen, 2016; Shen et al., 2012).

Another type of charging procedure that is commonly used for battery analysis applications is pulse charging. These profiles differ in the application of the pulsed charge, as they are differentiated by charging the battery using pulses solely and only replacing the CV phase with charge pulses. If used for charging applications, the idea for both profiles is to charge the battery in a relaxed way, as the pauses between the charge pulses allow lithium ions to properly intercalate into the negative electrode and thus reduce the risk of lithium-plating as well as allow a proper charge distribution (Amanor-Boadu et al., 2018a, b; Purushothaman et al., 2005; Savoye et al., 2012). During this relaxation time, overvoltage is reduced, which results in an improvement of the battery's life expectancy (AmanorBoadu et al., 2018a, b; Savoye et al., 2012).

While the pulsed charging profiles have several benefits in terms of reducing the stress experienced by the battery during charging, they rarely improve the charging time compared to the CCCV profile, as the pauses in between pulses further increase the charging time. Another pulse charging profile is called the reflex charge procedure, which has been developed to further reduce the stress experienced by the battery. During this procedure, the charge pulse is followed by a short break, which is then followed by a much shorter and higher discharge current. This aims to strip away lithium ions that have accumulated the negative electrode during the charge pulse and might run the risk of increasing lithium-plating. The procedure has been proven to effectively reduce lithium-plating, but its efficiency is not optimal, since the removed energy from the discharge pulse needs to be recharged during the next charge pulse (Pagar et al., 2021; Wang et al., 2016).

To reduce the charging time compared to the standard CCCV profile, researchers and the automotive industry alike investigate the challenges posed by fast charging. In general terms, it can be said that fast charging is an important feature to increase EV popularity as it will promote its user acceptance, as well as reduce the time needed to recharge commercially used vehicles such as buses, taxis and trucks (Hermann et al., 2019; Jochem et al., 2019; Kremzow-Tennie et al., 2021; Yang et al., 2018). However, due to the high currents required for fast charging, losses during charging increase in correlation with the charging current. 


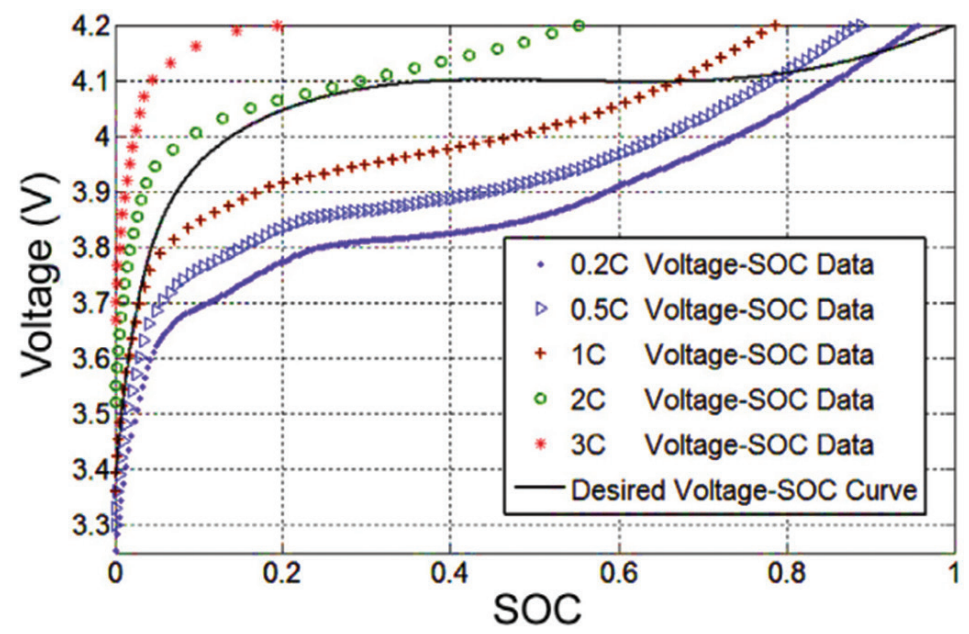

Fig. 7. CC charging at different C-Rates (Guo et al., 2015). CC, constant current.

Figure 7 displays the $\mathrm{CC}$ charge at different C-Rates, the charged capacity, and the resulting terminal voltage of the battery. The used charger is designed to stop charging when the cut-off voltage of $4.2 \mathrm{~V}$ is reached. During charging at high C-Rates the terminal voltage of the battery increases not only due to the capacity that has been charged but also due to the overpotential caused by the internal resistance and the charge current. Depending on the C-Rate this happens before a significant amount of capacity has been charged, e.g. Figure 7 at $3 \mathrm{C}$. Since the CC phase of the CCCV charge performs exactly what can be seen in Figure 7, it becomes clear that the C-Rate needs to be properly selected to reach the desired SOC in the fastest time. If only the fastest possible C-Rate is considered, most of the energy that is charged into the battery will be lost as ohmic and thus thermal losses (de Hoog et al., 2018; Guo et al., 2015; Kremzow-Tennie, 2021; Kremzow-Tennie et al., 2021; Pagar et al., 2021; Tomaszewska et al., 2019). A further issue arising from fast charging is the accelerated ageing of the battery, which becomes especially prominent when high C-Rates are used during higher SOC values. Due to these high currents, lithium-plating is promoted thus increasing the internal resistance and overpotential while also reduces the available capacity and the overall efficiency. Based on this knowledge the boost-charge (BC) profile was designed, which aims to counter lithium-plating through the use of a high charging current at low SOC values for a limited amount of time, which is then followed by a standard CCCV profile. Figure 1 shows how the lithium deposition potential behaves throughout the charge and it becomes clear that the risk of lithium-plating at lower SOCs is greatly reduced, thus underlining the idea of using the described procedure. The first research on $\mathrm{BC}$ profiles has been performed by the authors in a previous fast charging study and the results have shown that compared to the CCCVs overall efficiency of $92.3 \%$, overall efficiencies of $91 \%$ and $91.2 \%$ for two different BC profiles could be achieved. During cycle life testing the two BC profiles, which had been designed using a lithium deposition potential simulation, showed stronger ageing than its CCCV counterpart, which could be explained by the higher overall battery temperature reached and that the real lithium deposition potential might have been lower than simulated and thus lithium-plating was promoted during charging (Hermann et al., 2019). The two profiles did not implement the highest charging current at low SOCs, but at a later point which might also have promoted the accelerated ageing. Original BC research performed by (Notten et al., 2005) has shown that it is important to start the $\mathrm{BC}$ phase at $0 \% \mathrm{SOC}$ or close values. A further study into the thermal behaviour during CCCV fast charging and boost charging, during which the $\mathrm{BC}$ started at $0 \% \mathrm{SOC}$, have shown that depending on how the profile is designed, only a minimal difference between the maximum temperatures during the respective charges were reached (Kremzow-Tennie et al., 2021).

\subsection{Battery management systems (BMSs)}

A BMS is a system or device which is responsible for monitoring, switching and protecting individual battery cells or whole battery systems. It performs certain protection functions to ensure safe use of a battery system and prolongs the lifespan of the individual cells. (Duan et al., 2020; Marcos et al., 2020) The protection functions mitigate the following risks: they are susceptible to overtemperature, overvoltage (overcharging), under-voltage (deep discharge) and overcurrent respectively; overpower, which in the case of misuse results in a loss of battery capacity and in the 
worst case in a thermal runaway. For a safe operation of LIBs and to mitigate the risks given above, the following requirements must be met by a BMS (Aiello et al., 2015; Jossen et al., 1999; Lelie et al., 2018):

\begin{tabular}{ll}
\hline BMS Function/Requirement & Effect on the battery system \\
\hline \hline Temperature acquisition & Mitigate the risk of over- and under temperature \\
Highly precise voltage acquisition of individual cells, stacks respectively & Operate the cells within their voltage limits \\
modules, whole pack and the Direct Current (DC)-link voltage & Operate the cells within their current limit \\
Acquisition of current per stack or for the total pack & Start cooling, control charging, disconnect the system \\
Data communication, at least with high-level control system & Prolong the lifespan of the system \\
Appropriate magnitude of balancing currents & Ensure that a system can be disconnected under hazard conditions \\
Availability and switching performance of Contactors & Classification for second life applications \\
Data logging functionality, e.g. usage history &
\end{tabular}

An often unmentioned critical requirement is the intrinsic safety of the system concerning maintenance personnel, firefighters, and other professionals (Fechtner et al., 2016).

BMS rely heavily on specific hardware requirements to deploy software algorithms, such as the resolution for voltage readings; accordingly, they enable the determination of state variables such as the SOC, the SOH or the temperature of the entire battery, and a comprehensive overview is provided in (Liu et al., 2019; Rahimi-Eichi et al., 2013; Shen and Gao, 2019; Vidal et al., 2020; Waag et al., 2014). Besides the protection aspect mentioned above, a BMS has to fulfil the balancing of connected cells. Imbalance is a common problem of batteries, which is caused by internal and external effects. Internal effects are related to variances in the manufacturing process, impurity of materials, variations in impedance or self-discharge. External imbalance is caused through unequal heat distribution (causing different self-discharge rates) or unequal sourcing of protection integrated circuits draining the battery. Without balancing individual cell voltages will drift apart over time, resulting in a decrease in usable capacity. The used balancing methods can be either active or passive, but actually, every method is actively switched in the case of lithium-ion cells (Cao et al., 2008).

BMS for EV or further applications like stationary energy storage can be divided into active and passive balancing. Both methods aim to reduce capacity losses, enhance the lifetime of the batteries, and guarantee a constant and satisfactory performance during the use of the batteries (Uzair et al., 2021). Passive balancing is less expensive compared to active balancing, easier to realise, and widespread (Perisoara et al., 2018). Besides the aforementioned advantages, passive balancing has disadvantages such as energy losses, and active balancing is more effective against battery ageing. Nevertheless, the latter system has greater complexity and is more expensive (Uzair et al., 2021). Different topologies of passive cell balancing are known, such as systems with a fixed shunt resistor or and controlled shunt resistor (Uzair et al., 2021). The resistors integrated into passive balancing systems are used to control the stored energy of the cells, which are the most charged. Thus, the excess energy will be converted into thermal energy. Based on the method of passive balancing the charging time increase and electrical energy wastage caused by energy conversion from electrical to thermal energy leads to lower energy efficiency (Van et al., 2021). To quote example of a vehicle using passive balancing is the Peugeot iOn, which was used in different test scenarios conducted by the authors (Guenther et al., 2021; Scholz et al., 2021). For the monitoring of the Li-lon cells of the Peugeot iOn, the multicell battery stack monitor LTC6802-1 of Analog Devices is applied, which can measure 12 Li-lon Cells in series. For the balancing of the 88 cells of the Peugeot iOn, on-chip passive balancing switches, as well as MOSFETs, are integrated into the IC. Thus, overcharged cells can be discharged by the MOSFETs ('LTC6803 Linear Multicell Battery Monitor,' 2021).

Active balancing can be categorised by different balancing methods and underlying circuitry. The nondissipative balancing methods can be further split up into: Pack-to-Cell, Cell-to-Pack, Cell-to-Pack-to-Cell, Adjacent Cell-to-Cell and Direct Cell-to-Cell concerning the direction of the energy transfer. There are various hardware solutions already available to equalise charge imbalances of LIBs, a comprehensive overview is given in (Gallardo-Lozano et al., 2014; Popp et al., 2021; Shang et al., 2015). The used test vehicle, the Peugeot iOn, still uses a dissipative balancing with a reported power of approximately $400 \mathrm{~mW}$ per cell, assuming a cell voltage of 4.2 volts. A higher balancing power, hence a higher current, increases the stress on components and the used PCB caused by rising temperatures. To get around this, either greater resistances, in terms of power dissipation and its dimension, and additionally thicker cables have to be used or a change to a non-dissipative topology has 


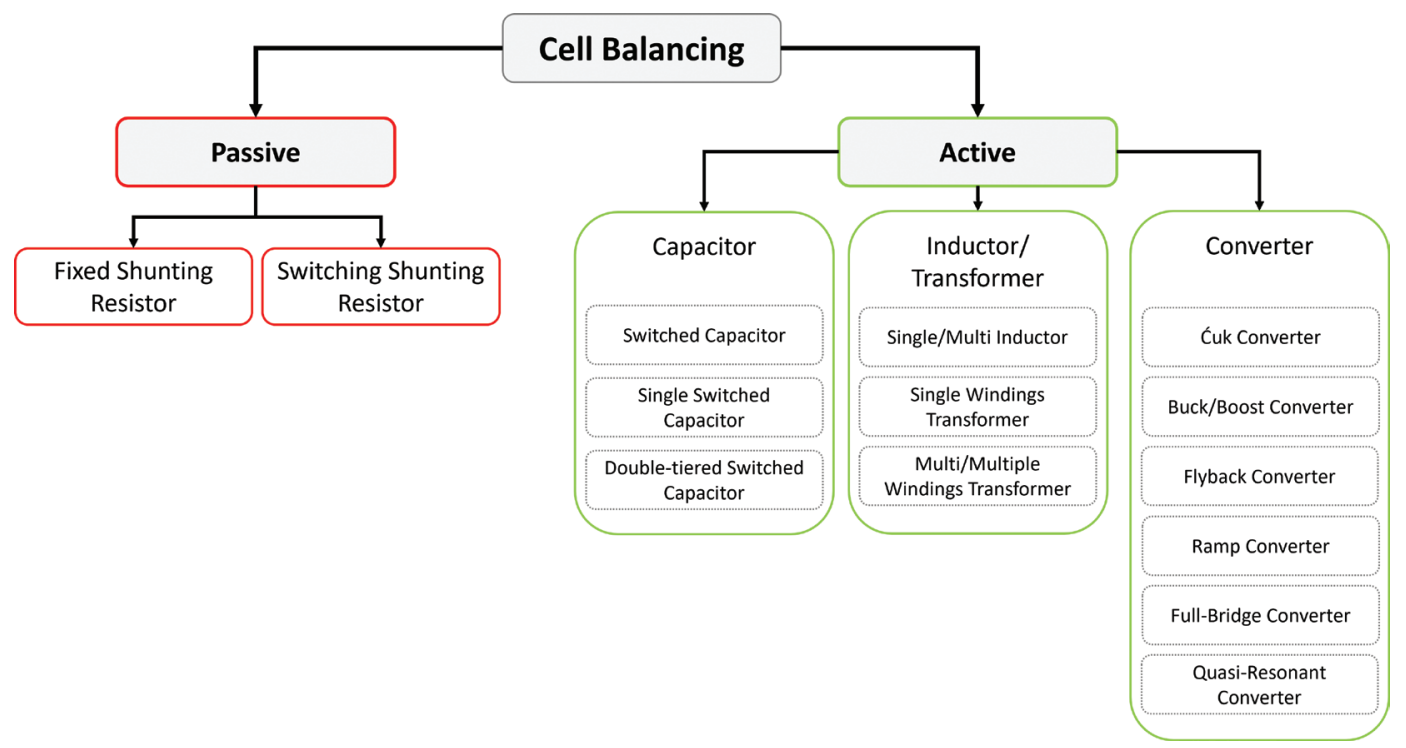

Fig. 8. Comparison of passive vs. active balancing in BMSs. Graphic based on (Daowd et al., 2011). BMSs, battery management systems.

to be made. The new non-dissipative topology comes with additional costs and weight, due to special components such as inductors and switches. More complex algorithms are also required to control these circuits and to redistribute the energy between the cells. So the typical approach for balancing in EV remains the dissipative balancing. (Lelie et al., 2018).

Furthermore, battery monitoring as well as balancing is an effective method to enhance the lifetime of batteries (Gabbar et al., 2021). In (Kremer et al., 2021), a strategy for active balancing is presented. This system has the goal, among others, to reduce the influence of the temperature on battery ageing. The positive effect of active balancing on battery ageing is emphasised by the authors of (Omariba et al., 2019). Furthermore, the importance of continuously monitoring the battery temperature in the context of battery ageing is also highlighted in (Lehtola and Zahedi, 2021). Therefore, a BMS can enhance the lifetime of batteries by measuring the battery currents, battery voltages and battery temperatures. The enhancement of the battery lifetime by the application of a BMS is also an ecological advantage (Gabbar et al., 2021).

\section{Data Collection and Battery Modelling}

Section 4 aims to display different ways of data collection that have been used to evaluate the efficiency influencing factors within this work. These are separated into laboratory battery testing, which allows the performance of precisely controlled battery tests, as well as real-world data collection which is performed by the installation of Controller Area Network Bus (CAN-Bus) loggers in different EVs to monitor their traction in real driving applications. At the electric vehicle institute of the Bochum University of Applied Sciences and the Chair of Electric Mobility and Energy Storage Systems of the University of Wuppertal, the authors of this publication research the electric behaviour of LIBs at cell and module levels. Using state-of-the-art Keysight Battery test systems, the two laboratories work hand in hand when it comes to different aspects of battery testing for research and customer projects. In compliance with internationally standardised battery test procedures, such as the ISO 12405 for electrically propelled vehicles, detailed analysis and characterisations are possible (ISO 12405-4, 2018). With currents of up to $\pm 100 \mathrm{~A}$ per channel and up to $\pm 800 \mathrm{~A}$ in parallel connection, the test system offers up to $2 \mathrm{kHz}$ of measurement frequency for current and voltage (Keysight, 2021). The usage of such laboratory test systems in combination with the real-world measurement data allows the authors to design battery models based on the data collected in a precisely controlled laboratory surrounding and compare the model results with data generated in real-world driving scenarios. At last in Section 4.3, the model designed from the literary analysis and the real-world data collection is presented and will show how the different components that have been presented in Section 3, influence each other. To further help the understanding of this, an example usage scenario is presented, displaying the interactions of the components for the application. 


\subsection{Laboratory battery testing}

To collect reference battery datasets, as well as test different controlled behaviours, such as during cyclic ageing with a continuous ageing cycle, laboratory battery test systems are crucial. At the electric vehicle institute, a cooling incubator from Binder ${ }^{\circledR}$ is used to perform the battery test in a controlled thermal environment, as well as ensure laboratory safety during testing. In combination with a ten-channel Keysight cell test unit, charge and discharge loads are applied to the cell, while cell voltage is measured on a secondary measurement line. Furthermore, the temperature of the cell is measured directly using PT1000 temperature sensors. The collected datasets are then stored either in a computer or in cloud storage like presented in (Hellwig et al., 2020) and can then be processed for further analysis.

Figure 9 displays the exemplary connection of a single prismatic cell (3.) to the Keysight Scienlab Battery Test System (2.) at the authors' laboratory. The cell is placed inside a Binder ${ }^{\circledR}$ KB 400 cooling incubator (1.), ensuring a controlled ambient temperature. Using the load line lines (7.) and (8.), the desired current be charged into or discharged from the battery. Via the voltage sense line (4.) and (5.) the battery's voltage is measured. Furthermore, the PT1000 temperature sense line (6.) measures the battery temperature and is connected to the battery case for optimal thermal measurement. To ensure operational safety, the measured voltage and temperature are continuously compared to a set of fixed values, such as $4.25 \mathrm{~V}$ as the maximum safety voltage, ensuring that the battery stays within the specified parameters at all times. Should one of the abortion criteria be harmed for a set period of time, testing is stopped on all channels and the cooling incubator lowers its internal temperature to $-5^{\circ} \mathrm{C}$ to reduce the battery's internal chemical activity.

Figure 10 shows the pulse power characterisation procedure of the ISO 12405-4 battery test procedure performed on a new Panasonic NCR18650B cell. This pulse power characterisation is performed using the previously displayed battery test system and is part of a long-term cycle life testing procedure. The pulse power characterisation is performed at different SOC values, namely $20 \%, 35 \%, 50 \%, 65 \%$ and $80 \%$ SOC. To achieve the SOC values, the cell is fully charged to its end of charge voltage, given a rest period of $1 \mathrm{~h}$, which is followed by a top-off charge aiming to compensate for any voltage losses from the previous charge. Afterwards the cell is discharged to the desired SOC value at which a high discharge and charge current are applied to the cell, thus measuring the voltage response. The measured voltage drop in charge and discharge direction is then measured and the desired information such as internal resistance, charge transfer resistance and polarisation resistance of the cell can be calculated from it. The discharge and charge pulses are then followed by a longer, but lower discharge pulse which discharges the cell to the next desired SOC level. At this level, the same pulses are applied, and the desired values can be calculated from them. Furthermore, the last voltage value before the pulses are applied, is considered the OCV value which in this case is recorded 30 min after the desired SOC level has been reached. This is done to let the cell chemistry relax and end most of the intercalation and diffusion processes that occur during the discharging process.

During the characterisation the cell's capacity is also measured using a defined charge and discharge current of one-third of the cell's standard C-Rate at different temperatures to evaluate its performance under different

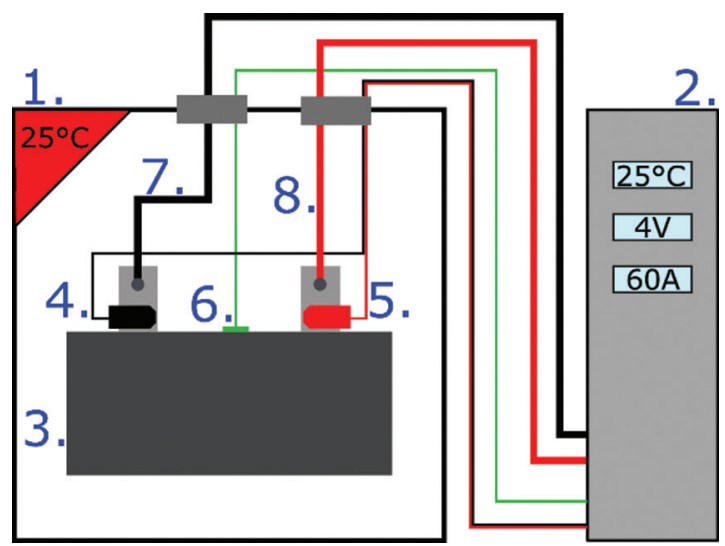

Fig. 9. Exemplary connection of a single prismatic battery cell to the Keysight Scienlab Battery Test System. 


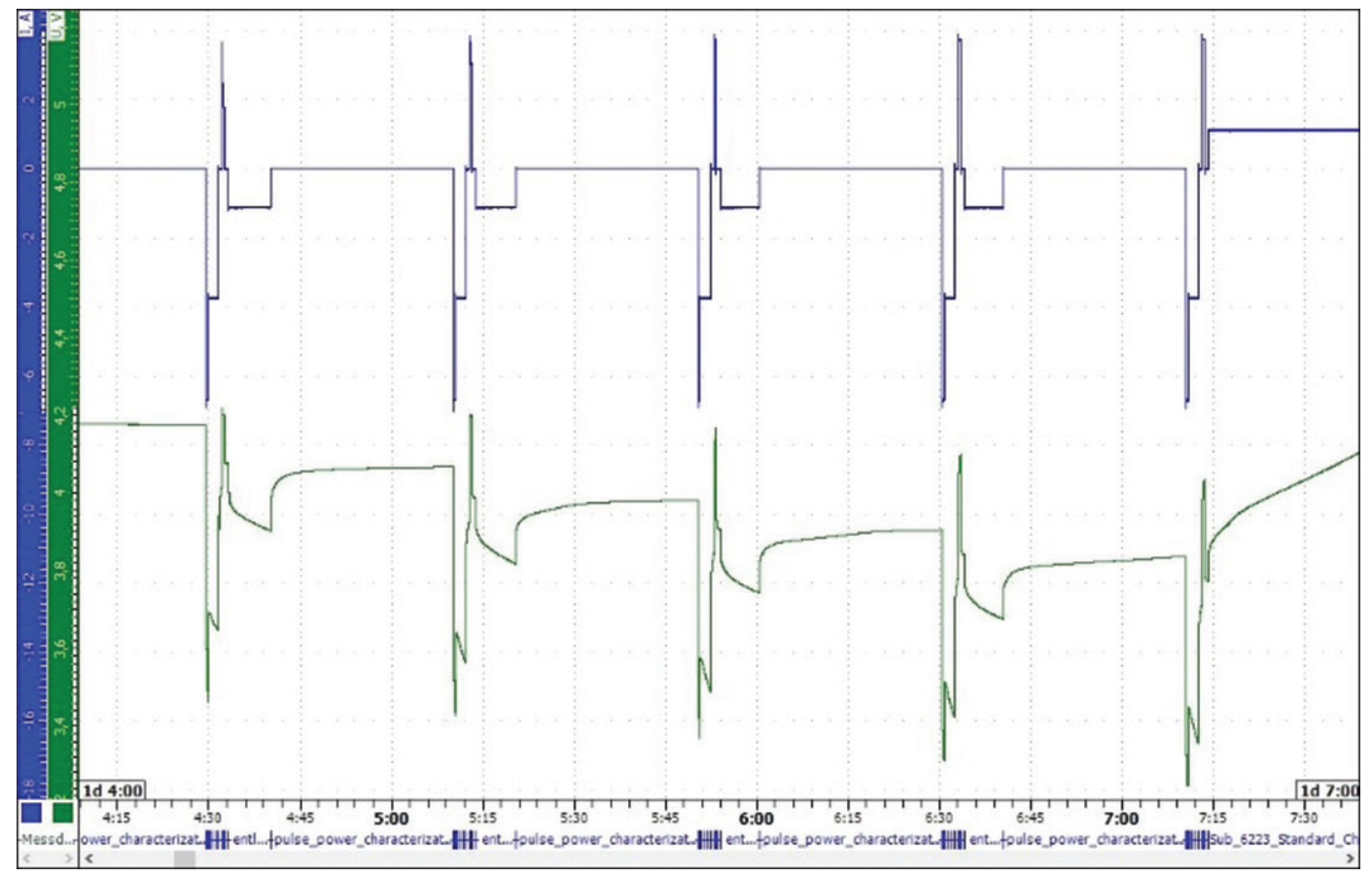

Fig. 10. Excerpt of a battery test programme performed to ISO 12405-4 compliance. Shown here is the pulse power characterisation of a Panasonic NCR18650B cell at one temperature.

environmental influences. As mentioned earlier the shown excerpt is from a long-term cycle life test during which the characterisation process is performed every after a fixed number of previously defined cycles. This offers precise monitoring of the cell's changing behaviour with its increasing age. In combination with the measured capacity of the cell, the obtained data from the pulse power characterisation are required to evaluate their influence on the overall efficiency. After the capacity and pulse power measurement have been performed the cell is cycled with a set number of pre-defined charge and discharge loads, after which another characterisation is performed. This is done until the desired $\mathrm{SOH}$ value, for automotive testing it is usually $80 \% \mathrm{SOH}$, is reached. After this life cycle analysis, the performance degradation of the cell over its cycle life for a set load profile is known and the changing behaviour of the efficiency influencing factor can be evaluated. Furthermore, the values obtained from such a characterisation process can then be used to feed a simulation model of the characterised battery, that can reproduce the performed measurements, as well as simulate load profiles that otherwise could not have been tested.

\subsection{Real-world data collection}

To be able to analyse the influences on the battery behaviour and its efficiency under real conditions, data recording is an important tool, e.g. in electric or partially EV, and it is also important in the application as stationary storage. In both cases, data on real use is collected which enables an assessment of possible losses and also, for example, future optimisation needs. When recording vehicle data, data logger units are usually used which are connected to the vehicle via the on-board diagnostics (OBD-II port). The OBD-II port is an interface to the vehicle's internal CAN-BUS, which is used for communication between the Electronic Control Units (ECUs) in the vehicle. In (Guenther et al., 2021), such a system was presented for recording and processing vehicle data using data loggers and applying cloud storage. When recording data for stationary storage, either data recording using data loggers (these typically have an intelligent and communication capable BMS), or smart meters can be used, which send their data via a backend system to an energy management system (EMS) such as in (Kalla et al., 2021) or (Rathor and Saxena, 2020).

\subsection{Principle model}

The literary analysis, in combination with the authors' own practical research, has identified efficiency influencing factors and allows to sort them in their order of significance. This can be used as advice for applications aiming to 


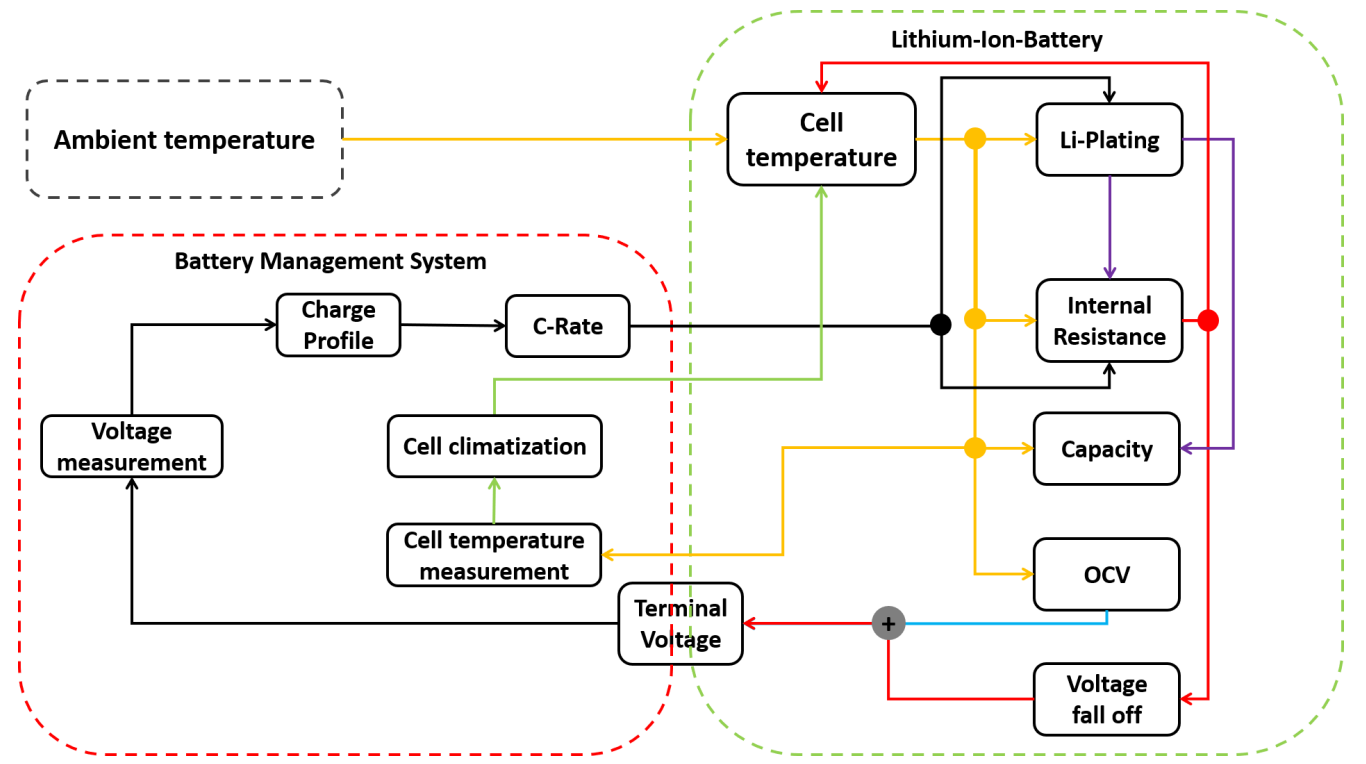

Fig. 11. Principle model of the different internal and external actors in a LIB and how they influence each other during charge and discharge. LIB, lithium-ion-battery.

achieve the highest efficiency when talking about the short-term effects or achieving the longest cycle life. It has to be noted, however, that the short-term and long-term effects interact with each other and thus influence each other.

Figure 11 displays the different actors inside and outside the battery and their influence on each other in a principle model. The two biggest influencing factors that have been identified in this research are the battery temperature and C-Rate used to charge or discharge the battery. Under consideration that a single charging process is observed, Figure 11 shall be explained using a detailed example.

As a basis for the explanation, it shall be assumed that the cell temperature and ambient temperature are the same value when the charge is started and that the charging procedure used is the standard CC-CV procedure.. When charging is started the BMS will define the C-Rate for the required charge following the charging conditions specified by the manufacturer, thus influencing cell temperature in combination with the internal resistance. The internal resistance, together with the OCV and available capacity, is strongly dependent on the temperature, as has been presented in the previous sections. In combination with the cell temperature, the C-Rate influences the quantity of lithium-ions that accumulate at the anode of the cell, thus influencing the severity of lithium-plating for the given charge. The amount of plated lithium, then influences the internal resistance, which increases due to the plated and therefore lost active material. This behaviour is especially crucial when the battery behaviour is analysed in a cycle life application, as measuring the occurred lithium-plating of a single charge is an extremely difficult process. The loss of active material furthermore results in the loss of available capacity. Depending on the C-Rate and the internal resistance, the voltage fall-off caused by the internal resistance of the cell influences the terminal voltage, which is measured by the BMS and can result in the charge being stopped before the battery is charged to the desired SOC, and similarly it can be seen in Figure 7 at high C-Rates in Section 3.6. The terminal voltage can be considered as an interface between the LIB and BMS and is next to the additionally measured cell temperature a crucial factor for the BMS' decision-making process. In the case of the exemplary used standard CC$\mathrm{CV}$ procedure, the cell will be charged with a CC until the upper end of charge voltage is reached and the charger then switches to the CV phase. In terms of efficiency influence, the CC phase results in greater losses, due to the higher charging current and the resulting voltage fall off at internal resistance, temperature increase and potential lithium plating. Should the cell temperature reach a limit, no matter if it is high or low, the BMS will coordinate the thermal management system to adapt the proper climatisation to bring the cell back or close to its desired operating temperature. Similar to temperature monitoring, the BMS measures the cell voltage and ensures that it is in the manufacturer specified range.

The displayed influences show the immediate effects of the different actors on each other. It has to be mentioned, that the figure does not include the battery's ageing, which has been left out for the sake of readability. In real life, 
each charge and discharge influences the battery's overall efficiency, as the described processes take place and thus promote the ageing of the battery.

\section{Conclusion and Further Research}

In this research, the authors have collected the necessary information to evaluate the different efficiency influencing factors relevant during the usage of LIBs. Through the detailed presentation of each of these, they aim to broaden the understanding of the different factors and how they influence each other. Based on the principle model shown in Figure 11, these influences are visualised and their relevance can be observed. The presented model is simplified to a point in time, as specific model, which does not consider ageing processes, and which would inhibit its understandability in this term of presentation. With this work, the authors have presented the literary basis, as well as the laboratory and real-world data collection required for the model to be created.

In the next steps following this publication, the authors aim to optimise an existing battery model that shall help to precisely simulate each of the influencing factors, for an even better understanding of their interaction and their influence on the battery's overall performance. Furthermore, the optimised model will help to adapt different influencing factors such as the charge profile and BMS to evaluate if the efficiency can be altered positively throughout the battery's lifetime, while still maintaining defined loads as they occur in EV and Second-Life applications.

\section{Author Contributions}

SK-T - Research concept and design; Collection and/or assembly of data; Data analysis and interpretation; Writing the article; Critical revision of the article. TS, PA, and FH - Collection and/or assembly of data; Data analysis and interpretation; Writing the article; Critical revision of the article. PF and SB - Critical revision of the article; Final approval of the article.

\section{References}

Aiello, O., Crovetti, P. S. and Fiori, F. (2015). Susceptibility to EMI of a Battery Management System IC for Electric Vehicles. In: 2015 IEEE International Symposium on Electromagnetic Compatibility (EMC). Presented at the 2015 IEEE International Symposium on Electromagnetic Compatibility EMC 2015, IEEE, Dresden, Germany, pp. 749754. doi: 10.1109/ISEMC.2015.7256257.

Albatayneh, A., Assaf, M. N., Alterman, D. and Jaradat, M. (2020). Comparison of the Overall Energy Efficiency for Internal Combustion Engine Vehicles and Electric Vehicles. Environmental and Climate Technologies, 24, pp. 669-680. doi: 10.2478/ rtuect-2020-0041.

Amanor-Boadu, J. M., Guiseppi-Elie, A. and SánchezSinencio, E. (2018a). The Impact of Pulse Charging Parameters on the Life Cycle of LithiumIon Polymer Batteries. Energies, 11(8), p. 2162. doi: 10.3390/en11082162.

Amanor-Boadu, J. M., Guiseppi-Elie, A. and SanchezSinencio, E. (2018b). Search for Optimal Pulse Charging Parameters for Li-lon Polymer Batteries Using Taguchi Orthogonal Arrays. IEEE
Transactions on Industrial Electronics, 65(11), pp. 8982-8992. doi: 10.1109/TIE.2018.2807419.

Arrhenius, S. A. (1889). Über die Reaktionsgeschwindigkeit bei der Inversion von Rohrzucker durch Säuren. Zeitschrift für Physikalische Chemie, 4, p. 226. doi: 10.1515/ zpch-1889-0116.

Barai, A., Uddin, K., Widanage, W. D., McGordon, A. and Jennings, P. (2018). A Study of the Influence of Measurement Timescale on Internal Resistance Characterisation Methodologies for Lithium-ion Cells. Scientific Reports, 8(1), p. 21. doi: 10.1038/ s41598-017-18424-5.

Barré, A., Deguilhem, B., Grolleau, S., Gérard, M., Suard, F. and Riu, D. (2013). A Review on Lithiumion Battery Ageing Mechanisms and Estimations for Automotive Applications. Journal of Power Sources, 241, pp. 680-689. doi: 10.1016/j. jpowsour.2013.05.040.

Bilansky, J. and Lacko, M. (2020). Design and Simulation of Cyclic Battery Tester. Power Electronics and Drives, 5, pp. 229-241. doi: 10.2478/pead-20200017. 
BU-502: Discharging at High and Low Temperatures [WWW Document]. (2010). Battery Univ. Available at: https://batteryuniversity.com/article/bu-502discharging-at-high-and-low-temperatures [Accessed 10 Dec. 2021].

Burkert, A., Fechtner, H. and Schmuelling, B. (2021). Interdisciplinary Analysis of Social Acceptance Regarding Electric Vehicles with a Focus on Charging Infrastructure and Driving Range in Germany. World Electric Vehicle Journal, 12(1), p. 25. doi: 10.3390/wevj12010025.

Cao, J., Schofield, N. and Emadi, A. (2008). Battery Balancing Methods: A Comprehensive Review. In: 2008 IEEE Vehicle Power and Propulsion Conference. Presented at the 2008 IEEE Vehicle Power and Propulsion Conference, pp. 1-6. doi: 10.1109/VPPC.2008.4677669.

Daowd, M., Omar, N., Van Den Bossche, P. and Van Mierlo, J. (2011). Passive and Active Battery Balancing Comparison Based on MATLAB Simulation. In: 2011 IEEE Vehicle Power and Propulsion Conference. Presented at the 2011 IEEE Vehicle Power and Propulsion Conference (VPPC). IEEE, Chicago, IL, USA, pp. 1-7. doi: 10.1109/VPPC.2011.6043010.

de Hoog, J., Jaguemont, J., Abdel-Monem, M., Van Den Bossche, P., Van Mierlo, J. and Omar, N. (2018). Combining an Electrothermal and Impedance Aging Model to Investigate Thermal Degradation Caused by Fast Charging. Energies, 11(4), p. 804. doi: 10.3390/en11040804.

Duan, J., Tang, X., Dai, H., Yang, Y., Wu, W., Wei, X. and Huang, Y. (2020). Building Safe LithiumIon Batteries for Electric Vehicles: A Review. Electrochemical Energy Reviews, 3, pp. 1-42. doi: 10.1007/s41918-019-00060-4.

Fechtner, H., Saes, K. H., Fechtner, E., Braun, T. and Schmülling, B. (2016). Clarification of the Training Requirements for Working on Electric Vehicles. International Journal of Advanced Corporate Learning, 9(1), p. 35. doi: 10.3991/ijac.v9i1.5635.

Gabbar, H. A., Othman, A. M. and Abdussami, M. R. (2021). Review of Battery Management Systems (BMS) Development and Industrial Standards. Technologies, 9(2), p. 28. doi: 10.3390/ technologies9020028.

Gallardo-Lozano, J., Romero-Cadaval, E., MilanesMontero, M. I. and Guerrero-Martinez, M. A. (2014). Battery Equalization Active Methods. Journal of Power Sources, 246, pp. 934-949. doi: 10.1016/j. jpowsour.2013.08.026.

Gao, Y., Jiang, J., Zhang, C., Zhang, W., Ma, Z. and Jiang, Y. (2017). Lithium-Ion Battery Aging Mechanisms and Life Model Under Different Charging Stresses. Journal of Power Sources, 356, pp. 103-114. doi: 10.1016/j.jpowsour.2017.04.084.

Guenther, L. H., Scholz, T., Pautzke, F., Fechtner, H., Schmuelling, B., Schelte, N., Severengiz, S., Hinz, M. and Bracke, S. (2021). Reliability Engineering of Electric Vehicle Powertrains: Data Collection and Analysis Based on Products in the Usage Phase. In: Proceedings of the 31st European Safety and Reliability Conference (ESREL 2021). Presented at the Proceedings of the 31st European Safety and Reliability Conference. Research Publishing Services, pp. 2573-2580. doi: 10.3850/978-98118-2016-8_183-cd.

Guo, Z., Liaw, B. Y., Qiu, X., Gao, L. and Zhang, C. (2015). Optimal Charging Method for Lithium Ion Batteries Using a Universal Voltage Protocol Accommodating Aging. Journal of Power Sources, 274, pp. 957964. doi: 10.1016/j.jpowsour.2014.10.185.

Hellwig, M., Scholz, T., Pautzke, F. and Tendyra, P. (2020). Das Vernetze Prüflabor NetLab. In: H. Proff, ed., Neue Dimensionen der Mobilität. Springer Fachmedien Wiesbaden, Wiesbaden, pp. 707-715. doi: 10.1007/978-3-658-29746-6_56.

Hermann, P., Zhang, C., Kremzow-Tennie, S. and Parzyszek, D. (2019). Das Forschungsprojekt D-See [di: si:] - Durchgängiges Schnellladekonzept für Elektrofahrzeuge 17.

Hossain Ahmed, S., Kang, X. and Bade Shrestha, S. O. (2015). Effects of Temperature on Internal Resistances of Lithium-Ion Batteries. Journal of Energy Resources Technology, 137(3), p. 031901. doi: 10.1115/1.4028698.

Hu, Y., Iwata, G. Z., Mohammadi, M., Silletta, E. V., Wickenbrock, A., Blanchard, J. W., Budker, D. and Jerschow, A. (2020). Sensitive Magnetometry Reveals Inhomogeneities in Charge Storage and Weak Transient Internal Currents in Li-Ion Cells. Proceedeings of the National Academy of Sciences, 117(20), pp. 10667-10672. doi: 10.1073/ pnas. 1917172117.

Iora, P. and Tribioli, L. (2019). Effect of Ambient Temperature on Electric Vehicles' Energy Consumption and Range: Model Definition and Sensitivity Analysis Based on Nissan Leaf Data. World Electric Vehicle Journal, 10(1), p. 2. doi: 10.3390/wevj10010002.

ISO 12405-4. (2018). ISO 12405-4 Electrically Propelled Road Vehicles - Test Specification for LithiumIon Traction Battery Packs and Systems - Part 4: Performance Testing. Geneva, Switzerland.

Jochem, P., Szimba, E. and Reuter-Oppermann, M. (2019). How Many Fast-Charging Stations do we 
need along European Highways? Transportation Research Part D: Transport and Environment, 73, pp. 120-129. doi: 10.1016/j.trd.2019.06.005.

Jossen, A., Späth, V., Döring, H. and Garche, J. (1999). Reliable Battery Operation - A Challenge for the Battery Management System. Journal of Power Sources, 84(2), pp. 283-286. doi: 10.1016/S03787753(99)00329-8.

Juarez-Robles, D., Vyas, A. A., Fear, C., Jeevarajan, J. A. and Mukherjee, P. P. (2020a). Overcharge and Aging Analytics of Li-lon Cells. Journal of the Electrochemical Society, 167(9), p. 090547. doi: 10.1149/1945-7111/ab9569.

Juarez-Robles, D., Vyas, A. A., Fear, C., Jeevarajan, J. A. and Mukherjee, P. P. (2020b). Overdischarge and Aging Analytics of Li-lon Cells. Journal of the Electrochemical Society, 167(9), p. 090558. doi: 10.1149/1945-7111/aba00a.

Kalla, P., Bakhtiarian, N., Grimm, D., Scholz, T., Grafe, D., Peric, S., Bauer, J., Teermann, A. and Pautzke, F. (2021). Energy Management in Metropolitan Emobility Charging Infrastructures EMEL. In: $\mathrm{H}$. Proff, ed., Transforming Mobility What Next?

Keil, P. and Jossen, A. (2016). Charging Protocols for Lithium-Ion Batteries and their Impact on Cycle Life-An Experimental Study With Different 18650 High-Power Cells. Journal of Energy Storage, 6, pp. 125-141.

Keysight. (2021). SL113XA/SL100XA Series Scienlab Battery Test System - Cell Level. [WWW Document]. Keysight. Available at: https:// www.keysight.com/de/de/products/hev-ev-gridemulators-and-test-systems/scienlab-battery-testsystems/sl1133a-sl100xa-series-scienlab-batterytest-system-cell-level.html [Accessed 13 Dec. 2021].

Khan, A. B., Pharm, V. L., Nguyen, T. T. and Choi, W. (2016). Multistage Constant-Current Charging Method for Li-Ion Batteries. In: 2016 IEEE Transportation Electrification Conference and Expo, Asia-Pacific (ITEC Asia-Pacific), pp. 381385.

Kim, U. S., Yi, J., Shin, C. B., Han, T. and Park, S. (2011). Modelling the Thermal Behaviour of a LithiumIon Battery During Charge. Journal of Power Sources, 196(11), pp. 5115-5121. doi: 10.1016/j. jpowsour.2011.01.103.

Kremer, P., Cigarini, F., Gohlich, D. and Park, S. (2021). Active Cell Balancing for Life Cycle Extension of Lithium-Ion Batteries under Thermal Gradient. In: 2021 IEEE/ACM International Symposium on Low Power Electronics and Design (ISLPED). Presented at the 2021 IEEE/ACM International
Symposium on Low Power Electronics and Design (ISLPED). IEEE, Boston, MA, USA, pp. 1-6. doi: 10.1109/ISLPED52811.2021.9502500.

Kremzow-Tennie, S. (2021). Modelling the Impact of Alternative Fast Charging Algorithms on the Thermal Behaviour of Lithium-Ion-Batteries. 1.

Kremzow-Tennie, S., Hellwig, M. and Pautzke, F. (2020). A Study on the Influencing Factors Regarding Energy Consumption of Electric Vehicles. In: 2020 21st International Conference on Research and Education in Mechatronics (REM). Presented at the 2020 21st International Conference on Research and Education in Mechatronics (REM). IEEE, Cracow, Poland, pp. 1-6. doi: 10.1109/ REM49740.2020.9313934.

Kremzow-Tennie, S., Pautzke, F. and Boehm, K. A. (2019). Einflussuntersuchung verschiedener Schnellladeverfahren auf die Lebensdauer von LiIon Batterien. doi: 10.13140/RG.2.2.11668.24963.

Kremzow-Tennie, S., Pautzke, F., Mecit, H., Scholz, T. and Schmuelling, B. (2021). A Suggestion Towards Improving Electric Vehicle Fast Charging. In: $\mathrm{H}$. Proff, ed., Making Connected Mobility Work. Springer Fachmedien Wiesbaden, Wiesbaden, pp. 251-261. doi: 10.1007/978-3-658-32266-3_14.

Lehtola, T. A. and Zahedi, A. (2021). Electric Vehicle Battery Cell Cycle Aging in Vehicle to Grid Operations: A Review. IEEE Journal of Emerging and Selected Topics in Power Electronics, 9(1), pp. 423-437. doi: 10.1109/ JESTPE.2019.2959276.

Lelie, M., Braun, T., Knips, M., Nordmann, H., Ringbeck, F., Zappen, H. and Sauer, D. U. (2018). Battery Management System Hardware Concepts: An Overview. Applied Sciences, 8(4), p. 534. doi: 10.3390/app8040534.

Liu, K., Li, K., Peng, Q. and Zhang, C. (2019). A Brief Review on Key Technologies in the Battery Management System of Electric Vehicles. Frontiers of Mechanical Engineering, 14(1), pp. 47-64. doi: 10.1007/s11465-018-0516-8.

Liu, Q., Du, C., Shen, B., Zuo, P., Cheng, X., Ma, Y., Yin, G. and Gao, Y. (2016). Understanding Undesirable Anode Lithium Plating Issues in Lithium-Ion Batteries. RSC Advances, 6(91), pp. 8868388700. doi: 10.1039/C6RA19482F.

Liu, X., Chen, Z., Zhang, C. and Wu, J. (2014). A Novel Temperature-Compensated Model for Power Li-lon Batteries with Dual-Particle-Filter State of Charge Estimation. Applied Energy, 123, pp. 263-272. doi: 10.1016/j.apenergy.2014.02.072.

LTC6803 Linear Multicell Battery Monitor [WWW Document]. (2021). Scribd. Available at: https:// 
www.scribd.com/document/54242037/LTC6803Linear-Multicell-Battery-Monitor [Accessed 13 Dec. 2021].

Lu, R., Yang, A., Xue, Y., Xu, L. and Zhu, C. (2010). Analysis of the Key Factors Affecting the Energy Efficiency of Batteries in Electric Vehicle. World Electric Vehicle Journal, 4(1), pp. 9-13. doi: 10.3390/wevj4010009.

Ma, S., Jiang, M., Tao, P., Song, C., Wu, J., Wang, J., Deng, T. and Shang, W. (2018). Temperature Effect and Thermal Impact in Lithium-Ion Batteries: A Review. Progress in Natural Science: Materials International, 28(6), pp. 653-666. doi: 10.1016/j. pnsc.2018.11.002.

Mahmud, A. H., Daud, Z. H. and Asus, Z. (2017). The Impact of Battery Operating Temperature and State of Charge on the Lithium-Ion Battery Internal Resistance. Jurnal Mekanikal, 8.

Marcos, D., Garmendia, M., Crego, J. and Cortajarena, J. A. (2020). Hazard and Risk Analysis on Lithiumbased Batteries Oriented to Battery Management System Design. In: 2020 IEEE Vehicle Power and Propulsion Conference (VPPC). Presented at the 2020 IEEE Vehicle Power and Propulsion Conference (VPPC). IEEE, Gijon, Spain, pp. 1-6. doi: 10.1109/VPPC49601.2020.9330888.

Matadi, B. P., Geniès, S., Delaille, A., Waldmann, T., Kasper, M., Wohlfahrt-Mehrens, M., Aguesse, F., Bekaert, E., Jiménez-Gordon, I., Daniel, L., Fleury, X., Bardet, M., Martin, J. F. and Bultel, Y. (2017). Effects of Biphenyl Polymerization on Lithium Deposition in Commercial Graphite/NMC Lithium-Ion Pouch-Cells during Calendar Aging at High Temperature. Journal of the Electrochemical Society, 164(6), pp. A1089-A1097. doi: 10.1149/2.0631706jes.

$\mathrm{Mu}, \mathrm{H}$. and Xiong, R. (2018). Modeling, Evaluation, and State Estimation for Batteries, in: Modeling, Dynamics and Control of Electrified Vehicles. Woodhead Publishing, Elsevier, pp. 1-38. doi: 10.1016/B978-0-12-812786-5.00001-X.

Nikolian, A., Firouz, Y., Gopalakrishnan, R., Timmermans, J. M., Omar, N., van den Bossche, P. and van Mierlo, J. (2016). Lithium Ion BatteriesDevelopment of Advanced Electrical Equivalent Circuit Models for Nickel Manganese Cobalt Lithium-Ion. Energies, 9(5), p. 360. doi: 10.3390/ en9050360.

Notten, P. H., het Veld, J. O. and Van Beek, J. R.(2005). Boostcharging Li-lon Batteries: A Challenging New Charging Concept. Journal of Power Sources, 145(1), pp. 89-94. doi: 10.1016/j. jpowsour.2004.12.038.
Noura, N., Boulon, L. and Jemeï, S. (2020). A Review of Battery State of Health Estimation Methods: Hybrid Electric Vehicle Challenges. World Electric Vehicle Journal, 11(4), p. 66. doi: 10.3390/wevj11040066.

Nuhic, A., Terzimehic, T., Soczka-Guth, T., Buchholz, M. and Dietmayer, K. (2013). Health Diagnosis and Remaining Useful Life Prognostics of Lithium-Ion Batteries Using Data-Driven Methods. Journal of Power Sources, 239, pp. 680-688. doi: 10.1016/j. jpowsour.2012.11.146.

Omariba, Z. B., Zhang, L. and Sun, D. (2019). Review of Battery Cell Balancing Methodologies for Optimizing Battery Pack Performance in Electric Vehicles. IEEE Access, 7, pp. 129335-129352. doi: 10.1109/ACCESS.2019.2940090.

Pagar, O., Darekar, M., Gawde, S., Bhartiy, J., Thakre, M. and Deshmukh, B. (2021). Comparative Evaluation of Fast Charging Systems for the Advanced Electric Vehicles with Pulse Charging \& Reflex Charging. SSRN Electronic Journal, doi: 10.2139/ssrn.3882535.

Perisoara, L. A., Guran, I. C. and Costache, D. C. (2018). A Passive Battery Management System for Fast Balancing of Four LiFePO4 Cells. In: 2018 IEEE 24th International Symposium for Design and Technology in Electronic Packaging (SIITME). Presented at the 2018 IEEE 24th International Symposium for Design and Technology in Electronic Packaging (SIITME), IEEE, Iasi, pp. 390-393. doi: 10.1109/SIITME.2018.8599258.

Petzl, M., Kasper, M. and Danzer, M. A. (2015). Lithium Plating in a Commercial Lithium-Ion Battery A Low-Temperature Aging Study. Journal of Power Sources, 275, pp. 799-807. doi: 10.1016/j. jpowsour.2014.11.065.

Pevec, D., Babic, J., Carvalho, A., Ghiassi-Farrokhfal, Y., Ketter, W. and Podobnik, V. (2020). A SurveyBased Assessment of How Existing and Potential Electric Vehicle Owners Perceive Range Anxiety. Journal of Cleaner Production, 276, p. 122779. doi: 10.1016/j.jclepro.2020.122779.

Pevec, D., Babic, J., Carvalho, A., Ghiassi-Farrokhfal, Y., Ketter, W. and Podobnik, V. (2019). Electric Vehicle Range Anxiety: An Obstacle for the Personal Transportation ( $r$ ) evolution?. In: 2019 4th International Conference on Smart and Sustainable Technologies (SpliTech). Presented at the 2019 4th International Conference on Smart and Sustainable Technologies (SpliTech), IEEE, Split, Croatia, pp. 1-8. doi: 10.23919/ SpliTech.2019.8783178.

Popp, A., Fechtner, H., Schmuelling, B., KremzowTennie, S., Scholz, T. and Pautzke, F. (2021). Battery 
Management Systems Topologies: Applications: Implications of Different Voltage Levels. In: 2021 IEEE 4th International Conference on Power and Energy Applications (ICPEA). Presented at the 2021 IEEE 4th International Conference on Power and Energy Applications (ICPEA). IEEE, Busan, Republic of Korea, pp. 43-50. doi: 10.1109/ ICPEA52760.2021.9639285.

Purushothaman, B. K., Morrison, P. W. and Landau, U. (2005). Reducing Mass-Transport Limitations by Application of Special Pulsed Current Modes. Journal of the Electrochemical Society, 152(4), p. J33. doi: 10.1149/1.1861172.

Rahimi-Eichi, H., Ojha, U., Baronti, F. and Chow, M. Y. (2013). Battery Management System: An Overview of Its Application in the Smart Grid and Electric Vehicles. IEEE Industrial Electronics Magazine, 7(2), pp. 4-16. doi: 10.1109/MIE.2013.2250351.

Rathor, S. K. and Saxena, D. (2020). Energy Management System for Smart Grid: An Overview and Key Issues. International Journal of Energy Research, 44(6), pp. 4067-4109. doi: 10.1002/ er.4883.

Redondo-Iglesias, E., Venet, P. and Pelissier, S. (2017). Impact of Battery Ageing on E-mobility Energy Efficiency. In: 2017 Twelfth International Conference on Ecological Vehicles and Renewable Energies (EVER). Presented at the 2017 Twelfth International Conference on Ecological Vehicles and Renewable Energies (EVER). IEEE, Monte-Carlo, Monaco, pp. 1-6. doi: 10.1109/ EVER.2017.7935882.

Reniers, J. M., Mulder, G. and Howey, D. A. (2019). Review and Performance Comparison of Mechanical-Chemical Degradation Models for Lithium-Ion Batteries. Journal of the Electrochemical Society, 166(14), pp. A3189A3200. doi: 10.1149/2.0281914jes.

Savoye, F., Venet, P., Millet, M. and Groot, J. (2012). Impact of Periodic Current Pulses on Li-lon Battery Performance. IEEE Transactions on Industrial Electronics, 59(9), pp. 3481-3488. doi: 10.1109/ TIE.2011.2172172.

Scholz, T., Kremzow-Tennie, S., Pautzke, F., Fechtner, H., Popp, A. and Schmuelling, B. (2021). Analysis of Cell-to-Cell Variation in a Battery Pack after Long Service Life Using Parameter Identification. In: 2021 IEEE 4th International Conference on Power and Energy Applications (ICPEA). Presented at the 2021 IEEE 4th International Conference on Power and Energy Applications (ICPEA), IEEE, Busan, Republic of Korea, pp. 38-42. doi: 10.1109/ ICPEA52760.2021.9639370.
Schuster, S. F., Bach, T., Fleder, E., Müller, J., Brand, M., Sextl, G. and Jossen, A. J. (2015). Nonlinear Aging Characteristics of Lithium-lon Cells Under Different Operational Conditions. Journal of Energy Storage, 1, pp. 44-53. doi: 10.1016/j. est.2015.05.003.

Shang, Y., Zhang, C., Cui, N. and Guerrero, J. M. (2015). A Cell-to-Cell Battery Equalizer With Zero-Current Switching and Zero-Voltage Gap Based on Quasi-Resonant LC Converter and Boost Converter. IEEE Transactions on Power Electronics, 30(7), pp. 3731-3747. doi: 10.1109/ TPEL.2014.2345672.

Shen, M. and Gao, Q. (2019). A Review on Battery Management System From the Modeling Efforts to its Multiapplication and Integration. International Journal of Energy Research, 43(10), pp. 50425075. doi: 10.1002/er.4433.

Shen, W., Vo. T. T. and Kapoor, A. (2012). Charging Algorithms of Lithium-lon Batteries: An Overview. In: 2012 7th IEEE Conference on Industrial Electronics and Applications (ICIEA). Presented at the 2012 7th IEEE Conference on Industrial Electronics and Applications (ICIEA), IEEE, Singapore, Singapore, pp. 1567-1572. doi: 10.1109/ICIEA.2012.6360973.

Tomaszewska, A., Chu, Z., Feng, X., O'Kane, S., Liu, X., Chen, J., Ji, C., Endler, E., Li, R., Liu, L and Li, Y. (2019). Lithium-lon Battery Fast Charging: A Review. ETransportation, 1, p. 100011. doi: 10.1016/j.etran.2019.100011.

Trentadue, G., Lucas, A., Otura, M., Pliakostathis, K., Zanni, M. and Scholz, H. (2018). Evaluation of Fast Charging Efficiency under Extreme Temperatures. Energies, 11(8), 1937. doi: 10.3390/en11081937.

Uzair, M., Abbas, G. and Hosain, S. (2021). Characteristics of Battery Management Systems of Electric Vehicles with Consideration of the Active and Passive Cell Balancing Process. World Electric Vehicle Journal, 12(3), p. 120. doi: 10.3390/wevj12030120.

Van, C. N., Vinh, T. N., Ngo, M. D. and Ahn, S. J. (2021). Optimal SoC Balancing Control for Lithium-Ion Battery Cells Connected in Series. Energies, 14(10), p. 2875. doi: 10.3390/en14102875.

Vidal, C., Malysz, P., Kollmeyer, P. and Emadi, A. (2020). Machine Learning Applied to Electrified Vehicle Battery State of Charge and State of Health Estimation: State-of-the-Art. IEEE Access, 8, pp. 52796-52814. doi: 10.1109/ ACCESS.2020.2980961.

Waag, W., Fleischer, C. and Sauer, D. U. (2014). Critical Review of the Methods for Monitoring 
of Lithium-Ion Batteries in Electric and Hybrid Vehicles. Journal of Power Sources, 258, pp. 321339. doi: 10.1016/j.jpowsour.2014.02.064.

Wang, S., Fan, Y., Stroe, D. I., Fernandez, C., Yu, C., Cao, W. and Chen, Z. (2021). Lithium-Ion Battery Characteristics and Applications. In: Battery System Modeling. Elsevier, pp. 1-46. doi: 10.1016/ B978-0-323-90472-8.00003-2.

Wang, Z., Wang, Y., Rong, Y., Li, Z. and Fantao, L. (2016). Study on the Optimal Charging Method for Lithium-Ion Batteries Used in Electric Vehicles. Energy Procedia, 88, pp. 1013-1017. doi: 10.1016/ j.egypro.2016.06.127.

Wang, D., Bao, Y. and Shi, J. (2017). Online LithiumIon Battery Internal Resistance Measurement Application in State-of-Charge Estimation Using the Extended Kalman Filter. Energies, 10(9), p. 1284. doi: 10.3390/en10091284.

Xing, Y., He, W., Pecht, M. and Tsui, K. L. (2014). State of Charge Estimation of Lithium-Ion Batteries Using the Open-Circuit Voltage at Various Ambient Temperatures. Applied Energy, 113, pp. 106-115. doi: 10.1016/j.apenergy.2013.07.008.

Xu, B., Oudalov, A., Ulbig, A., Andersson, G. and Kirschen, D. S. (2018). Modeling of Lithium-Ion
Battery Degradation for Cell Life Assessment. IEEE Transactions on Smart Grid, 9(2), pp. 1131-1140. doi: 10.1109/TSG.2016.2578950.

Yang, X. G. and Wang, C. Y. (2018). Understanding the Trilemma of Fast Charging, Energy Density and Cycle Life of Lithium-Ion Batteries. Journal of Power Sources, 402, pp. 489-498. doi: 10.1016/j. jpowsour.2018.09.069.

Yang, X. G., Zhang, G., Ge, S. and Wang, C. Y. (2018). Fast Charging of Lithium-Ion Batteries at all Temperatures. Proceedings of the National Academy of Sciences, 115(28), pp. 7266-7271. doi: 10.1073/pnas.1807115115.

Zhang, R., Xia, B., Li, B., Cao, L., Lai, Y., Zheng, W., Wang, H., Wang, W. and Wang, M. (2018). A Study on the Open Circuit Voltage and State of Charge Characterization of High Capacity Lithium-Ion Battery Under Different Temperature. Energies, 11(9), p. 2408. doi: 10.3390/en11092408.

Zhu, J., Mathews, I., Ren, D., Li, W., Cogswell, D., Xing, B., Sedlatschek, T., Kantareddy, S. N., Yi, M., Gao, T. and Xia, Y. (2021). End-of-Life or Second-Life Options for Retired Electric Vehicle Batteries. Cell Reports Physical Science, 2(8), p. 100537. doi: 10.1016/j.xcrp.2021.100537. 